OPEN ACCESS

Edited by:

Emily C. Adams,

University of Alabama in Huntsville,

United States

Reviewed by:

Xinxuan Zhang,

George Mason University,

United States

Tasnuva Rouf,

University of California, Berkeley,

United States

*Correspondence:

Ufuoma Ovienmhada

ufuoma@mit.edu

Specialty section

This article was submitted to

Climate Services,

a section of the journal

Frontiers in Climate

Received: 30 May 2021

Accepted: 13 August 2021

Published: 09 September 2021

Citation:

Ovienmhada U, Mouftaou F and Wood D (2021) Inclusive Design of Earth Observation Decision Support

Systems for Environmental

Governance: A Case Study of Lake

Nokoué. Front. Clim. 3:717418.

doi: $10.3389 /$ fclim.2021.717418

\section{Inclusive Design of Earth Observation Decision Support Systems for Environmental Governance: A Case Study of Lake Nokoué}

\author{
Ufuoma Ovienmhada ${ }^{1 *}$, Fohla Mouftaou ${ }^{2}$ and Danielle Wood ${ }^{1}$ \\ ${ }^{1}$ MIT Media Lab, Space Enabled Research Group, Massachusetts Institute of Technology, Cambridge, MA, United States, \\ ${ }^{2}$ Green Keeper Africa, Cotonou, Benin
}

Earth Observation (EO) data can enhance understanding of human-environmental systems for the creation of climate data services, or Decision Support Systems (DSS), to improve monitoring, prediction and mitigation of climate harm. However, EO data is not always incorporated into the workflow for decision-makers for a multitude of reasons including awareness, accessibility and collaboration models. The purpose of this study is to demonstrate a collaborative model that addresses historical power imbalances between communities. This paper highlights a case study of a climate harm mitigation DSS collaboration between the Space Enabled Research Group at the MIT Media Lab and Green Keeper Africa (GKA), an enterprise located in Benin. GKA addresses the management of an invasive plant species that threatens ecosystem health and economic activities on Lake Nokoué. They do this through a social entrepreneurship business model that aims to advance both economic empowerment and environmental health. In demonstrating a Space Enabled-GKA collaboration model that advances GKA's business aims, this study first considers several popular service and technology design methods and offer critiques of each method in terms of their ability to address inclusivity in complex systems. These critiques lead to the selection of the Systems Architecture Framework (SAF) as the technology design method for the case study. In the remainder of the paper, the SAF is applied to the case study to demonstrate how the framework coproduces knowledge that would inform a DSS with Earth Observation data. The paper offers several practical considerations and values related to epistemology, data collection, prioritization and methodology for performing inclusive design of climate data services.

Keywords: earth observation, water hyacinth, climate data services, decision support systems, design

\section{INTRODUCTION}

Today, approximately 3 billion people, about half of the world's 7.5 billion population, live within $200 \mathrm{~km}$ of a coastline. Low-Elevation Coastal Zones, defined here as the contiguous area along the coast that is less than $10 \mathrm{~m}$ above sea level, are home to 10 percent of the world's population. This zone covers just 2 percent of the world's land area (McGranahan et al., 2007). In addition to their intrinsic value, these zones have immense extrinsic value through the provision of benefits, known as Ecosystem Services. Examples of ecosystem services that lake and coastal zones provide include transportation 
and access to trade, fishing, and temperature regulation. Clean freshwater bodies may also provide an ecosystem service in the form of water for consumption. This human-environmental interaction is complex and dynamic because there are benefit dependencies or competing interests in these ecosystems. "Benefit Dependence" refers to the idea that the benefits an individual or group are interested in will dictate their concept of an ecosystem service. For example, water is sometimes used as a dumping ground for waste disposal; this use of water could be seen as an ecosystem service for one actor (Boyd and Banzhaf, 2007). On the other hand, other actors who interact with the same water body and rely on fishing for subsistence, may find that the waste disposal affects this important economic activity, which could also be considered an ecosystem service. Another example that illustrates this is the benefits derived from tropical rain forests. At a global level, tropical rainforests are recognized for their value in regulating climate through carbon sequestration. Meanwhile, other stakeholders may perceive the primary value of forests to be fuel. Since different stakeholders perceive different benefits from the same ecosystem, the benefits can at times be conflicting or outright antithesis (Turner et al., 2003; Hein et al., 2006). These examples illustrate the complexity of theses socio-ecological systems and the importance of "Environmental Governance," a concept in political ecology and environmental policy that advocates sustainability as the supreme consideration for managing all human activities-political, social, and economic. "Environmental governance" is not equivalent to "government." Environmental Governance refers to the interventions aimed at changing knowledge, decision-making and behaviors as it pertains to the environment. The term is inclusive of actions taken by government and non-government organizations, businesses, communities, or individuals. International accords like the Paris Agreement, legislation, local decision-making structures and traditional cultural practices can all be forms through which environmental governance is pursued. The Sustainable Development Goals (SDGs), the 2030 agenda for sustainable development adopted by all United Nations Member States in 2015, is an example of Environmental Governance. The SDGs set priorities that the member states choose to adopt in order to advance global and local sustainability.

Complex human-environmental systems are important to study because shifts or threats to the ecosystem services of these coastal areas, and inadequate processes for environmental governance can lead to social conflict and/or economic devastation. Sea level rise provides excellent case studies of the relationship between shifts in an ecosystem, anthropogenic pressure, and socio-environmental impacts. For example, in 2019, the Indonesian President Joko Widodo announced that the country would move its official capital away from Jakarta. Factors motivating this move include rapid population growth and environmental change due to sea level rise. The population growth has put unsustainable pressure on the city's urban water supply which has led to over-pumping of the city's groundwater resources (Dsikowitzky et al., 2016). The overpumping combined with sea level rise has led to land subsidence. The island is physically sinking at an estimated 25 centimeters per year (National Public Radio, 2019). Currently, about 40 percent of Jakarta is located below sea-level (Pratomo, 2016). Moving the capital has dramatic economic implications, estimated to require the equivalent of 32.7 Billion USD. Another example can be seen in Louisiana among the Isle de Jean Charles, LA, band of the Biloxi-Chitimacha- Choctaw tribe. Sea level rise and increased flooding in Louisiana has caused the tribe to consider options to either adapt or relocate. This has produced conflict around desired outcomes within the community (Northern Arizona University, 2008). One group feels culturally attached to the land and would prefer an adaptive strategy, while another group feels that the community carries the culture irrespective of the physical location and wants to migrate. From these examples, it's clear how environmental change can lead to social conflict and/or economic devastation. With population growth rising globally, the pressure and tensions over resources in these already fragile systems are exacerbated.

Design methods provide tools to help people understand the world, their contexts, and to take initiative to design products, technologies, or services to advance their needs. Earth Observation technologies provide tools to quantitatively understand the natural world and how to sustainably operate within it (Martin, 2008). When design is combined with EO, there is an opportunity to positively impact decision making on Environmental Governance. These types of tools are commonly called Decision Support Systems (DSS). There are two concrete ways that EO data can improve environmental governance. First, data can help to describe features of an environmental phenomenon and potential positive or negative relationships between multiple variables. If these relationships are revealed, it is possible to react to those relationships with new policy or management methods. Second, data can enable groups to evaluate options for environmental governance and select policies that meet stakeholder needs and concerns. Often there are multiple viable choices to choose from in a decision. Data can enable a decision-maker to model or forecast different choices and select for a desired outcome.

NASA SERVIR provides several examples of DSS that use EO data to improve environmental governance (SERVIR Service Catalog). A joint initiative of National Aeronautics and Space Administration and United States Agency for International Development, SERVIR works in partnership with leading regional organizations world-wide to help countries use information provided by Earth observing satellites and geospatial technologies for managing climate risks and land use. For example, SERVIR has collaborated with the Ghana local government to operationalize optical data showing deforestation and burn signatures to identify and monitor charcoal production sites, toward an overall effort for more sustainable environmental planning (SERVIR Service Catalogue, 2018). SERVIR uses satellite and GIS data to address other topics as well such as Food Security and Flood forecasting. Work by SERVIR spans several regions including South America, Himalayas, East Africa, West Africa and Southeast Asia, empowering decision makers to act on local issues.

Despite these benefits and positive stories of DSS, data is not always incorporated into the workflow for decision-makers for a multitude of reasons from awareness, to interpretability, 
accessibility, and cost. Co-author Wood describes lack of funds, expertise and equipment as other factors that can contribute to a country or organization's inability to use space technologies (Wood and Weigel, 2014). The purpose of this paper is to address financial, technological and informational challenges that historically socioeconomically and environmentallymarginalized communities face in designing and implementing DSS for Environmental Governance. The study also aims to demonstrate collaborative models that address historical power imbalances between communities. This paper argues that explicit consideration of design methods and collaborative models can address barriers to inclusive DSS adoption. To advance this argument, this paper develops a definition of "inclusivity," considers the many different methods for product, service and technology design, and critiques the methods for its applicability to Environmental Governance design challenges. The design and collaborative approach this paper recommends is then applied to a case study in Cotonou, Benin.

\section{MATERIALS AND METHODS}

Addressing Research Objective 1, "Describe a process that a community or organization could take to design a DSS" begins with a literature review on existing design methods. There are many design and engineering methods that are commonly used in product, service, and technology development. These methods fundamentally originate from different communities and schools of thought including art, computer science, or engineering communities. It is important to examine the different methods because each method has strengths, weaknesses or biases in the way information is gathered or analyzed. Thus, the same method may not be reliable for different types of project pursuits or contexts. This section discusses and critiques several different types of Technology or Product Design Methods and provides a rationale for the method selected - the Systems Architecture Framework (SAF).

\section{Review and Critique of Technology Design Methods}

IDEO, a design and consulting firm founded in 1991, defines Design Thinking as "a human-centered approach to innovation that draws from the designer's toolkit to integrate the needs of people, the possibilities of technology, and the requirements for business success." The five step Design Thinking process includes:

1. Empathize - personify end-users to understand their challenges and needs

2. Define - concisely summarize the end-user challenges that need to be solved

3. Ideation - selecting solutions to prototype with end-users

4. Prototype - prototyping solutions with increasing fidelity through iterations

5. Test - test the prototypes with end-users.
The Design Thinking methodology often uses tools and techniques including sketching, mock-ups, post-it notes, journey maps, storyboarding and role-playing (Johnson et al., 2007; Diana et al., 2012). The Design Thinking process has had radical success in changing the way that product and service ideas are developed. It is particularly strong for rapid generation of creative and innovative solutions to problems. However, a caution of Design Thinking is that it can sometimes be used routinely and without nuance or adaptation of the steps for the specific application (Norman, 2005). Empathy can be pursued through research methods that do not actually formally include the end users in the design process. The Design Thinking process is not inherently collaborative. It also, by encouraging "concision" and rapid prototyping in its method description, does not necessitate a robust formal description of the end-users and the systems within which they exist or interact with.

Another design methodology, User-Centered Design, has similar steps to Design Thinking but is often applied to user interface design in particular. The User-Centered Design process emphasizes improving the usability, accessibility, and pleasure provided from interacting with a product or technology. It, like Design Thinking, often includes steps of prototype demonstration with the user group and processes that commonly include flowchart construction as a means to communicate the design of systems. Like Design Thinking, this process is not inherently collaborative, nor does it encourage formal system descriptions in the empathy phase of the method.

Community-Centered Design is an older method that looks at the community of users from an observational standpoint. The researcher or designer aims to generate viewpoints or observations of the unanimous behavior of a community and generate designs in response to those observations. A method that has attempted to extend the class of design methods to see the user community as not only users but designers themselves is participatory design (Sanders and Stappers, 2008). Participatory design is an approach that actively involves the people who are being served through direct engagement with the stakeholders at every step. Key techniques and tools used in this approach are the use of workshops, storytelling and co-designed physical artifacts to generate a shared design language among the designers and stakeholders.

The Transition Design framework, developed by Terry Irwin Gideon Kossoff and Cameron Tonkinwise at Carnegie Mellon University's School of Design, is an approach that emphasizes the description and visualization of complex problems, improving upon those weaknesses of Design Thinking and Participatory Design (Irwin, 2015). It advocates design-led societal transition toward more sustainable futures through the application of four steps: (1) Vision; (2) Theories of Change; (3) Mindset \& Posture; (4) New Ways of Designing. Transition Design aims to set intentions for radically different future systems and outline actionable steps to achieve those futures. Of the approaches discussed thus far, Transition Design is most explicit about using visualizations to conceptualize and formally describe the relationships and challenges within a community as a system.

The previously mentioned SERVIR initiative, jointly pursued by NASA and USAID, uses a handbook called the Service 
Planning Toolkit that stems from a group of engineering design methods that emphasize "system" (Service Planning Toolkit, 2017). This handbook walks users through the steps to gather information about needs and to transform need into datapowered tools. SERVIR encourages mapping and flowchart work to properly describe the system of interest. While the SERVIR approach has strength in its formality, the toolkit prescribes that local collaborators should be chosen based on criteria including "relevant technical knowledge" and "resources to fund and maintain the service." These criteria are explicitly exclusive in who is considered to have knowledge and value in the design process of a technology or product.

Systems Architecture stands apart from all of the described design methods in that it emphasizes understanding the organization of processes and relationships in an enclosed system, while maintaining an open and inclusive approach to knowledge generation and valuation. Systems Architecture originates from a subset of the engineering community that sought to address weaknesses in traditional engineering methods by bringing more contextual and stakeholder thinking into the engineering design process (Rechtin and Maier, 2010; Cameron et al., 2016). Rechtin 1991 describes a System as a "a set of different elements so connected or related as to perform a unique function not performable by the elements alone." With this definition in mind, a system can be any group of interconnected elements such as complex products like a car, infrastructure systems such as the healthcare industry, a company or organization, a set of countries in a collaborative relationship etc. An architecture description is a formal description and representation of the comprehensive parts of a system. Crawley et al. define Systems Architecture as an "abstract description of the entities of a system and the relationships between those entities" (Crawley et al., 2004). The Systems Architecture Framework (SAF) as adapted by Dr. Danielle Wood is a generic model that captures decision making and design for complex systems. It is particularly useful for describing human-designed, technologyenabled systems that provide public services such as access to infrastructure or education. The SAF framework is marked by 6 steps:

1. Describe the Context at international, national, and local levels

2. Identify and categorize Stakeholders

3. Describe Stakeholder Needs, Desired Outcomes and Values

4. Identify Desired System Objectives

5. Describe current Functions and Form

6. Describe proposed Functions and Forms and evaluate them according to the System Objectives

The zeroth step of the SAF involves describing a clear Boundary of the System of interest. The System Boundary should be large enough to fully encompass the System of Interest but narrow enough such that the system is comprehensible to the engineer or designer. The first step of the SAF Framework begins with a need to critically understand the Context and

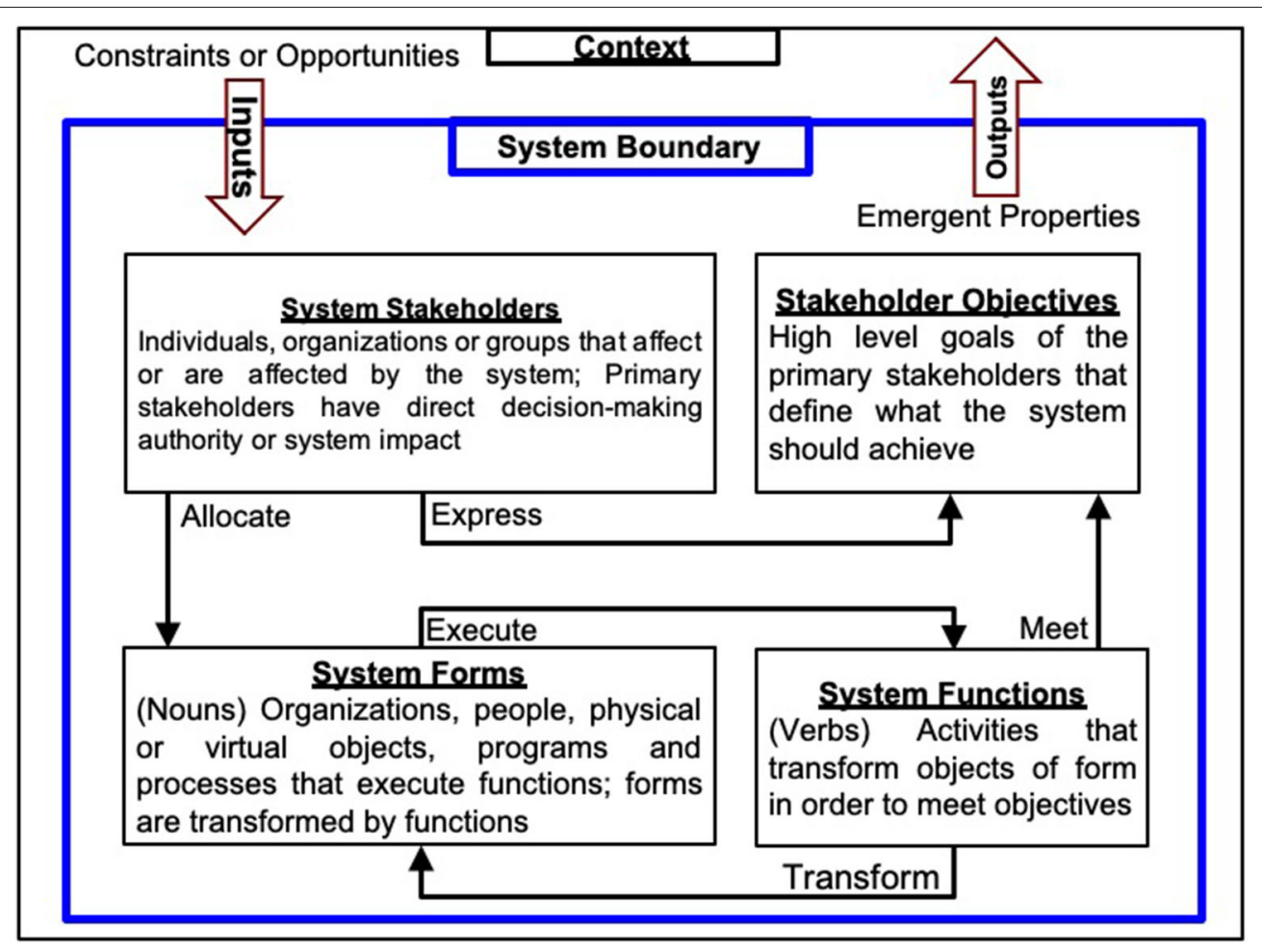

FIGURE 1 | The Systems Architecture Framework adapted by Wood can be used to design or evaluate a system created by humans with strong links to the environment and technology. Credit: Danielle Wood. 
history of an organization, community or system. Context can include local, country-level and international information. This step can be addressed through a mixture of literature review or strategies such as observation and interview. Stakeholders can be separated into three categories: Primary, Secondary and Tertiary. Drawing from work by Cameron et al. (2016), Professor Wood defines Primary Stakeholders as those that make direct decisions about the design of the System. Secondary Stakeholders are those that have influence on the Primary Stakeholders via authority or funding. Tertiary Stakeholders are those that exert little or no control over the system but are impacted by it. Once the Stakeholders in a system are identified, a variety of research techniques such as flowchart creation, mapping, and agent-based modeling can be used to describe Stakeholder Needs and Desired Outcomes. Needs are defined generally as anything a stakeholder is lacking, whether related to the system or not. Desired Outcomes are the end states a stakeholder desires to attain. Values, recorded from the perspective of each stakeholder, are things that stakeholders hold as benefit in relation to needs and desired outcomes. Next in Step 4, while considering stakeholder Values, a set of System Objectives are defined from the broader list of Desired Outcomes. To meet System Objectives, Forms are allocated to execute Functions. A Function is what a System does: its actions, outcomes, or outputs. A Form is what the system is-the instrument of the Function or the object that is transformed by the Function. For the example of a car as a System, the engine (Form) executes the Function of converting energy to move the vehicle. The descriptions in Step 5 help to fully characterize the System and its activities. Applications of the SAF commonly include visual representations of the system parts described in Steps 3, 4, and 5. These visual representations are helpful for describing the dependencies and structures of the different parts in a system. Figure 1 shows an example of visualizing the relationships between the System Boundary, Context, Stakeholders, Forms, Functions and Stakeholder Objectives. The "Outputs" are the emergent properties of the system. This can be a product, a service, policy outcome etc. Step 6 of a Systems Architecture Analysis proposes new Functions and Forms, which can be a new system, policy recommendation or technology design to address the desired System Objectives. The design can then be evaluated according to the System Objectives. Figure 2 shows an example of visualizing all of the steps of the SAF together.

This framework is helpful for identifying the themes, patterns, and priorities of a system in an organized fashion which can lead to a better engineering or design solution. Crawley et al. describes four concrete strengths of a Systems Architecture approach (Crawley et al., 2004):

1. "Architecture is a way to understand complex systems" An architecture can be used to understand the dependencies within complex systems and the failure modes within a system.

2. "Architecture is a way to design complex systems" - An architecture can be used by designers to create systems with desired behaviors and structures. Knowledge of a systems architecture can enable a designer to more efficiently identify opportunities to alter the system to behave with desired goals.
3. "Architecture is a way to design standards and protocols to guide the evolution of long-lived systems" - An architecture can be used to establish and communicate a baseline for how similar systems should behave.

4. "Architecture is a way to manage complex systems" Complexity within systems can mean that there are hidden or changing interconnections within a system. If these interconnections are not revealed, managing the system can be challenging and have unintended consequences emerge.

This section discussed a variety of art-based and engineeringbased methods for designing products and technology systems. Some of the methods are particularly strong for rapid design and creative solutions. While other methods are particularly strong for understanding complex workflows and systems.

\section{Selection of Technology Design Method}

While the art-based design methods discussed in section Review and Critique of Technology Design Methods certainly have their strengths, they generally assume the user to be individuals or groups of people with homogenous needs. The SAF accounts for systems comprised of complex populations and interactions between populations. As described in the introduction, Environmental Governance can involve conflicting Benefit Dependencies and social conflict related to environmental shifts, which increases the complexity of addressing any needs. Thus, for the application of designing a DSS for environmental governance, the system is sufficiently complex that the SAF is selected as the strongest design. The SAF framework is applied to a case study of Lake Nokoué in Cotonou, Benin, with local partner, Green Keeper Africa (GKA). GKA is a social enterprise led by Managing Director Dr. Fohla Mouftaou. GKA employs a combination of physical removal and commercialization to manage the effects of the invasive water hyacinth plant on Lake Nokoué (PRB, 2020). While the SAF implicitly has an open approach to knowledge generation, the authors begin the case study by defining several shared Values for accounting for power imbalances in order to explicitly build inclusivity into the research with GKA:

- Both partners aim to set project priorities based on needs identified within the host community. GKA spends time with the community of Ganvié near Cotonou, Benin, to learn local needs. Both Space Enabled and GKA share ideas based on the resources, skills, technologies and network that we bring. We iterate as a collaborative team to consider potential priorities and we aim to set objectives that will be mutually beneficial while meeting needs as defined by members of the local host community. To understand these priorities, we've engaged in five rounds of meetings - three in Cotonou and three in Boston.

- Green Keeper Africa invites Space Enabled to contribute to work in their community. Space Enabled trusts Green Keeper Africa to advise about how to operate within the local context and how to connect with relevant stakeholders. Space Enabled asks for the advice of Green Keeper Africa on when it is appropriate to interact with local communities, political 


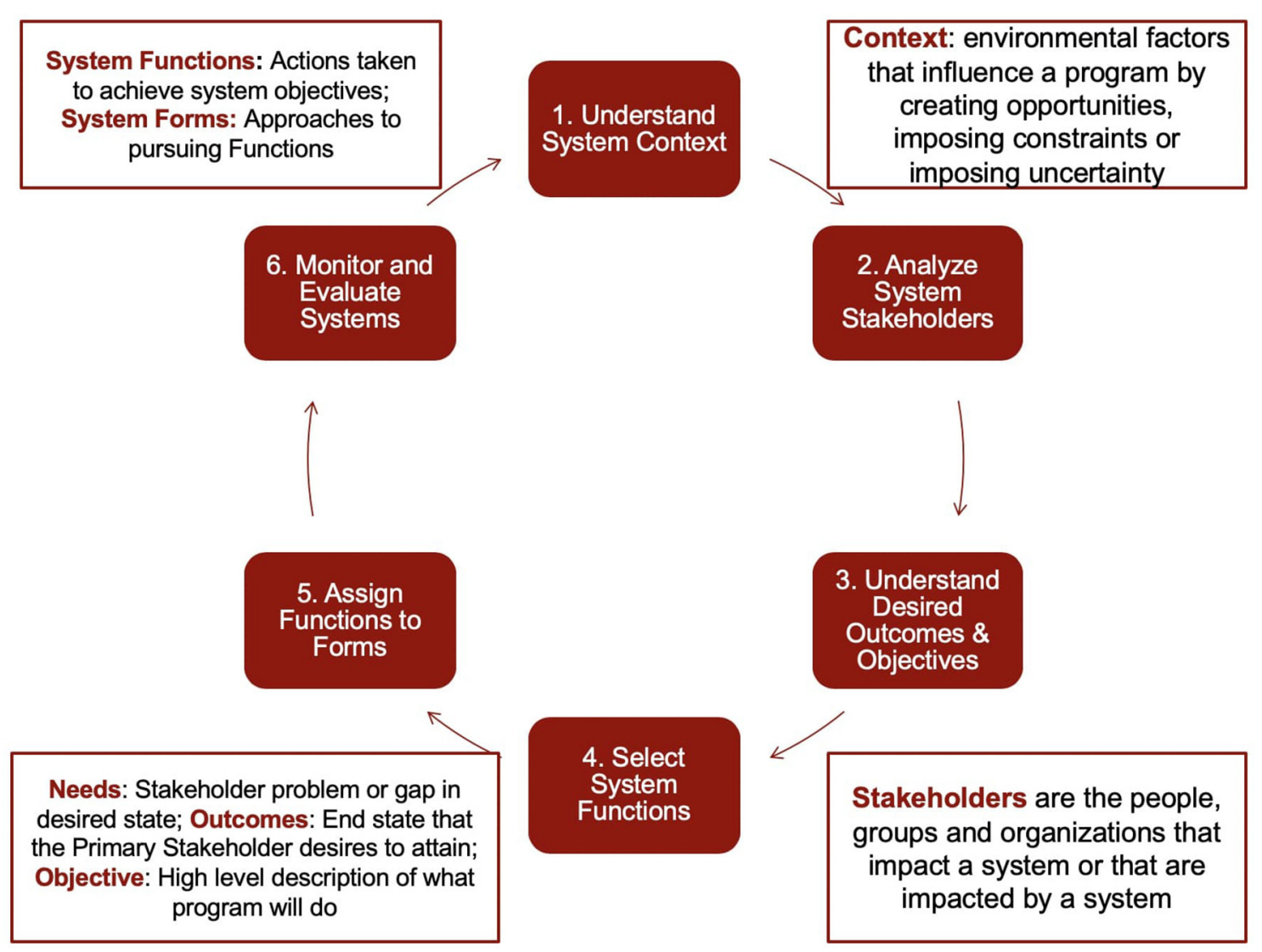

FIGURE 2 | The Systems Architecture Framework provides six steps to design and evaluate a complex, socioenvironmental system. Credit: Danielle Wood.

leaders, and other potential colleagues. The team takes special care when engaging with community representatives that may have traditionally faced social disadvantage in areas that use non-dominant languages, live in poverty, or live outside of influential urban districts. When field work is necessary, the preparation includes asking for permission from GKA and requests that they join for the activity if possible.

- Both Space Enabled and Green Keeper Africa aim to learn from the expertise of local organizations about the project topic. Together the two teams spend time learning about the work of local academic and government teams with related knowledge. For example, the teams meet with hydrologists from the University Abomey-Calavi and the National Institute of Water that have extensively studied the Lake.

- Space Enabled and Green Keeper Africa make decisions collaboratively regarding how to fundraise, speak publicly about the work, spend funds, bring on new team members and set project objectives. Space Enabled seeks permission from GKA before taking outputs from the work in the field into the community. Thus, if Space Enabled is giving presentations or writing publications, the preparation includes asking for permission from GKA and requests that they join as coauthors or co-presenters if possible.

\section{RESULTS}

In this section, the SAF is applied to elucidate locally defined priorities for a DSS to support Environmental Governance on Lake Nokoué. For the zeroth step, we define the System Boundary. The System of interest is Green Keeper Africa (GKA) and their interactions with Lake Nokoué. It includes all aspects of GKA's business model, their interactions with the physical environment, and their local objectives as a company. The SAF is applied to understand the Context Green Keeper Africa works within, the Functions and Forms of GKA organizationally, and to elucidate the Desired Outcomes for environmental governance from the perspective of GKA.

\section{Step One: Describe the Context}

Benin, formally the Republic of Benin, is a country in West Africa. Benin borders Nigeria (East), Togo (West), Burkina Faso (Northwest) and Niger (Northeast). Before the country Benin was created, there existed the Kingdom of Dahomey, which occupied a smaller extent than modern boundaries of Benin. As Dahomey became established in West Africa, it also became established in transatlantic slave trade (Monroe, 2011). Europeans, such as the Portuguese and French, set up trading 


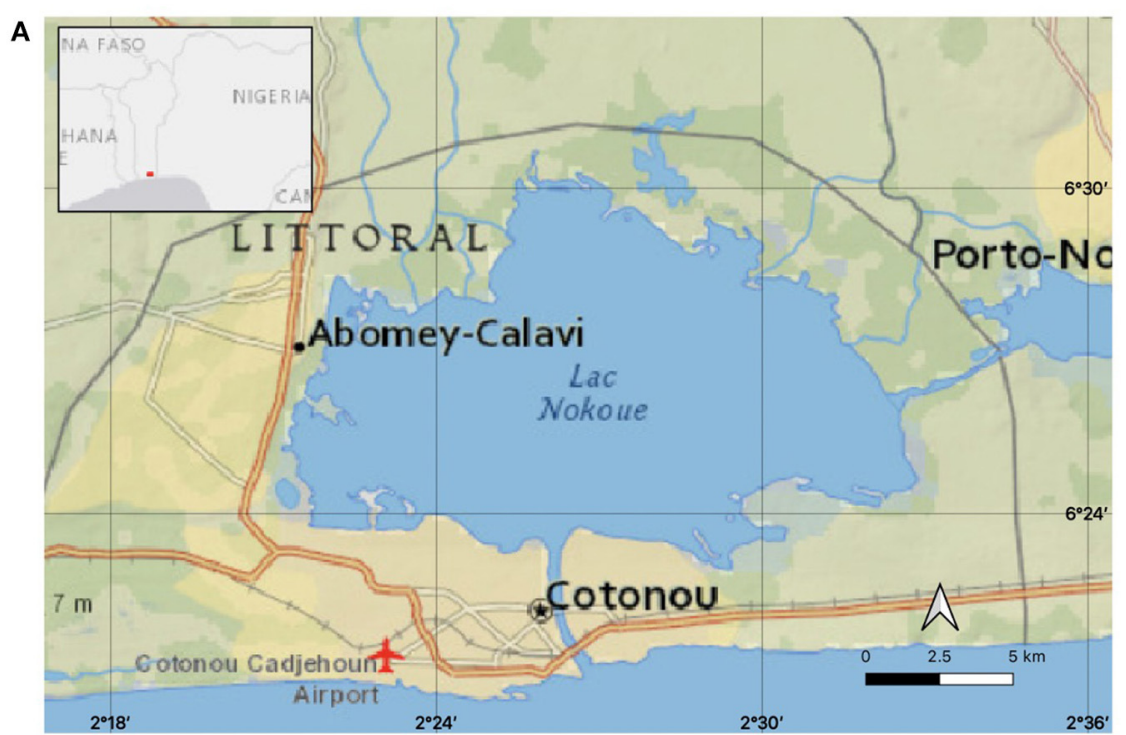

B

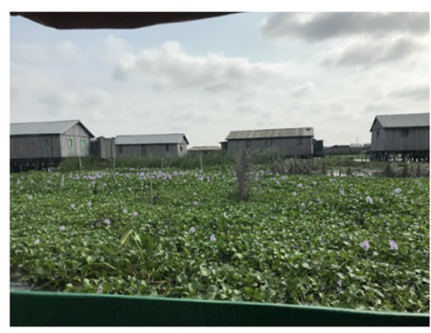

C

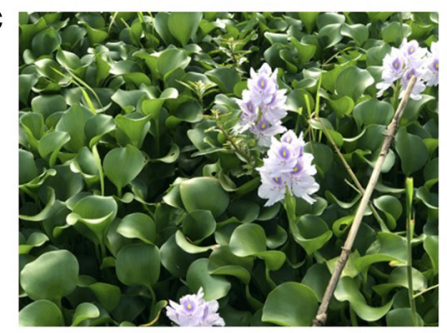

D

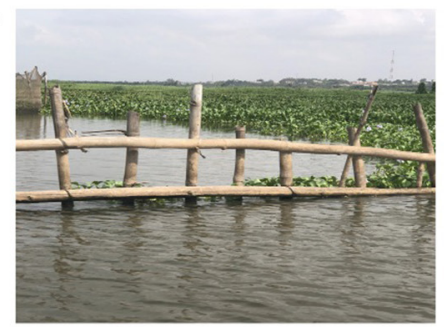

FIGURE 3 | Map of Lake Nokoue in Benin (A) with images of water hyacinth (B,C) and acadja fishing ponds (D). Credit: The Authors.

posts along the coast of cities such as Porto-Novo, Ouidah, and Cotonou. The French became the protectorates of Dahomey's "main cities and ports" until becoming a French colony in 1872. The Republic of Benin became an independent country in 1960. Today, Benin is home to a population of 13 million, comprised of primarily Fon, Adja, and Yoruba ethnic groups. The economic capital is Cotonou, located on the southern coast (The World Factbook, 2021).

Lake Nokoué is directly north of Cotonou (see Figure 3A). At an estimated area of $160 \mathrm{~km}^{2}$ during dry season, Lake Nokoue is the largest lake in Benin (Weis, 2020). However, the size of the lake varies seasonally. Lake depths range between 0.4 and $3.4 \mathrm{~m}$ (Weis, 2020). The climate of the Lake Nokoué area is tropical, with temperatures maintained between 24 and $32^{\circ} \mathrm{C}$ year-round. Benin has two rainy and two dry seasons. The principal rainy season is from April to late July, with a shorter, less intense rainy period from late September to November. Lake Nokoué faces several challenges relevant to environmental governance. One challenge is with an invasive plant species, the Eicchornia Crassipes, commonly known as the water hyacinth (see Figures 3B,C). The water hyacinth is one of the most problematic plants for water ecosystems. The water hyacinth is native to the Amazon Basin in Latin America (Barrett and Forno, 1982). In the 1900's, it spread throughout the Tropics and now reaches as far north and south as the $40^{\circ}$ latitudes (Center, 1994). At present the water hyacinth has invaded 5 continents, including Africa (Lowe et al., 2000). While the water hyacinth performs ecosystem services such as reduction of suspended particles, dissolved impurities and heavy metals like mercury and lead (Dunigan et al., 1975; Verma et al., 2003), it is largely seen as problematic because of the devastating impacts it has on other aspects of an ecosystem. The plant is very competitive; two plants can multiply to 120,000 in 3 months (Holm et al., 1969). The plant grows in dense mats which can block transportation routes and hinder photosynthesis of underwater plants by reducing light penetration into the water (see Figure 3B) (Gichuki et al., 2012). These mats of hyacinth can contribute to water volume loss through rapid evapotranspiration - 2 to 8 times more than a free water body surface (Holm et al., 1969). Other environmental impacts include decline in water clarity, increased potential for flooding and a decline in the diversity of aquatic life (Mailu et al., 1998). When the plant dies, the decomposition process absorbs exorbitant amounts of oxygen which can dramatically alter fishing populations. Economic impacts experienced by communities have included increases in transportation costs, difficulties in electricity generation and water extraction, fewer tourists and blockage of irrigation canals (Mailu et al., 1998). 
Due to the devastating impacts of water hyacinth proliferation, many biological, chemical and mechanical methods (all examples of environmental governance) have been attempted to control its growth in different regions of the world. In terms of biological control, six different arthropods, including weevils, moths and mites, have been released around the world to act as predators of the water hyacinth (Charudattan, 2001; Julien et al., 2001). These biological methods have shown limited success but often cannot achieve the necessary scales to eradicate the water hyacinth on their own (Julien et al., 2001). Application of herbicides has been largely ineffective and unsustainable. The plant is resistant to most herbicides. Even for herbicides that do kill the plant, the rapid mortality treatment causes the plant to sink and disperse. Given that the plant proliferates through seed germination, any plants that were not killed can still spread throughout the water body and repopulate (Hill and Olckers, 2000). Mechanical/Physical removal is possible but requires large-scale labor and mobilization of resources. Sometimes mechanical removal can negatively impact the habitats and health of benign species (Mangas-Ramírez and Elías-Gutiérrez, 2004). People have also tried to motivate water hyacinth removal by commercializing the plant into products such as paper, weaved baskets and more (Jafari, 2010). Variable climate conditions, nutrient regimes and hydrological features make the efficacy of these different solutions vary widely across the world (Hill and Olckers, 2000).

To illustrate the scale of the problem in Benin specifically, in 1999 a survey was done in Benin that estimated the yearly income of 200,000 people to be reduced by 84 million USD due to the impacts of water hyacinth. Lost revenues were mostly in trade of food crops and fish (De Groote et al., 2003). At the time, those losses represented nearly 10 percent of the GDP contribution from the city of Cotonou, the economic hub of Benin. Another notable cost that the water hyacinth inflicts is the cost of control measures. For example, the annual cost of biological control of the water hyacinth on Lake Nokoué in 1999 was estimated at 2.09 million USD (De Groote et al., 2003). This problem continues today with negative impacts across environmental and social dimensions in addition to economic.

Another challenge that Benin faces with environmental governance pertains to a traditional fish farming practice known as "acadja." Acadja are artificial systems of wood and brush aimed at enhancing fish production by providing additional substrata for development of plants and animals upon which the fish will feed (see Figure 3D) (Niyonkuru and Lalèyè, 2010). The acadja method was initiated by fishermen in Benin, more than 100 years ago with an original aim to replace the mangrove, which was known to contribute to fish production, but was disappearing due to deforestation driven by urbanization and human consumption (Welcomme, 1971). The major advantage of acadja is that the fish yield per unit area is much higher than in open water (Welcomme, 2002). However, the intensification of the acadja fishing practice in the last few decades has led to the accumulation of tons of dry woods in Lake Nokoué. The decay of the woods combined with the accumulation of water hyacinth debris has contributed to lake depth shallowing and disturbed the habitats of marine species (Djihouessi and Aina, 2018). The disturbance to fish species occurs because the acadja are selective for some fish species but not all resulting in a progressive shift in the lake ecosystem system from freshwater species to marine water species and from insectivorous fish to detritivorous fish (Niyonkuru and Lalèyè, 2010; Djihouessi and Aina, 2018). In

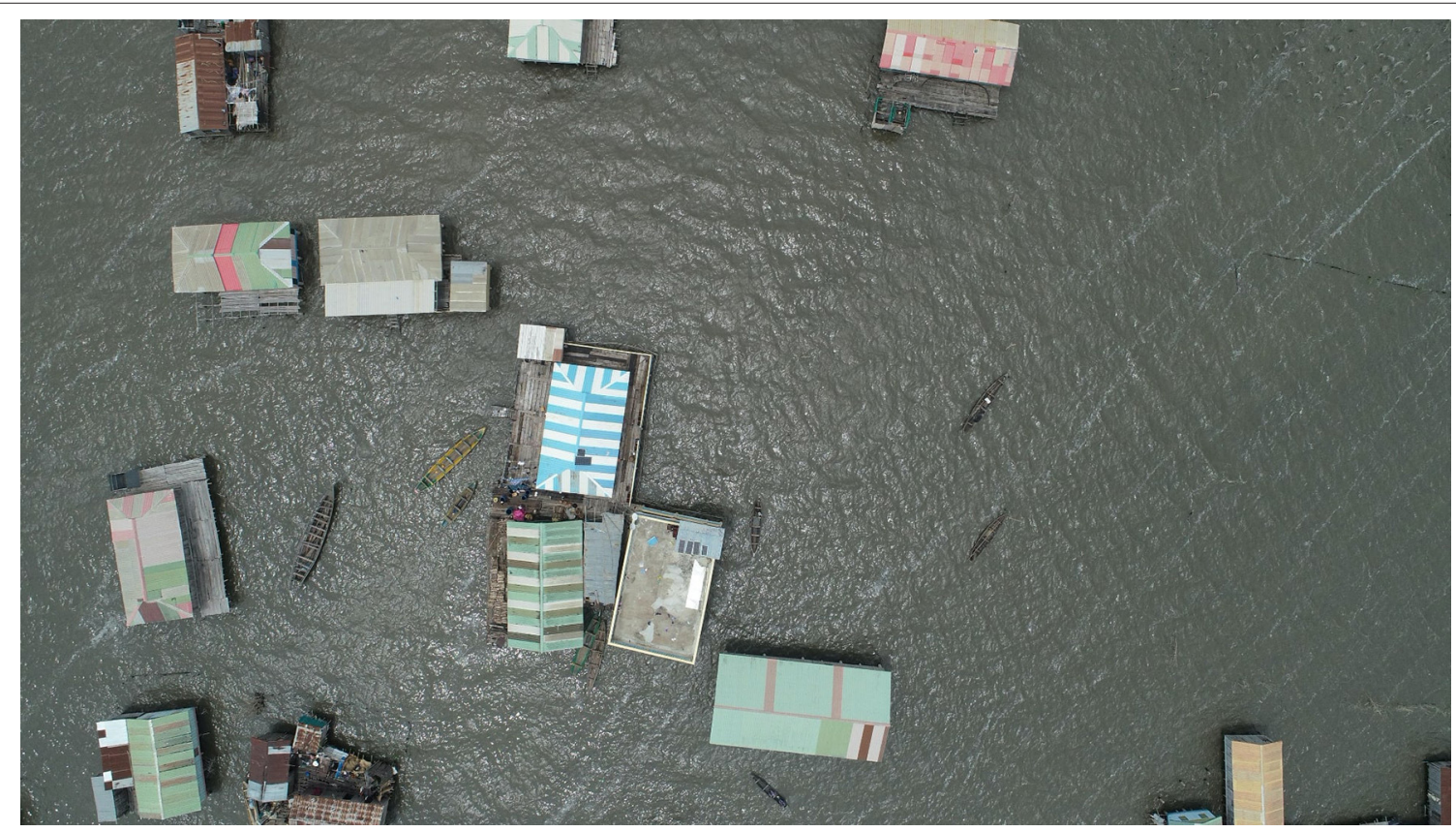

FIGURE 4 | Aerial image of the village of Ganvié on Lake Nokoué. Credit: The Authors. 
addition, the nutrients contributed by the acadja increases water hyacinth production (Welcomme, 1971). Some acadja actually utilize mangroves, contributing to the destruction of important mangrove habitats.

A critical part of understanding the Environmental Governance challenges posed by the water hyacinth and acadja is the interaction between the lake and local community. There are human settlements that are built on the lake (see Figure 4). These settlements date back to the slave trade era where people escaped to Lake Nokoue to flee slave traders; the surrounding swamp lands provided an ideal refuge for them (Soumonni, 2003). Today, this community is home to $\sim 70,000$ people. These villages have experienced a growth in their touristic interest leading to new services such as hotels and restaurants. The lake is a vital source for conducting activities such as agriculture, fishing, trade, sand extraction and transportation. Today, about 2 million people from the cities of Cotonou, Abomey-Calavi and Porto-Novo interact with the lake through these activities. Fishing is the most predominant activity done on the Lake. In 2005, the fish caught in Lake Nokoué was estimated at 50,000 tons per $\mathrm{km}^{2} /$ year in 2005 , making this ecosystem the most productive lake in West Africa (Villanueva et al., 2006). Nutrient loads that are produced from fishing activity and inadequate sanitation are important to understand as they connect to water hyacinth proliferation by creating ideal chemical conditions for growth. A study of these communities determined that the homes did not have adequate sanitation infrastructures. Thus, it is assumed that 100 percent of wastewater and excretion are directly rejected into the lake. Its nutrient load is estimated at 108 tons/year of total nitrogen and 18 tons/year of total phosphorous (Djihouessi and Aina, 2018).

Another feature relevant to the Environmental Governance issue is the lake hydrology. The lake has a canal that connects the lake to the ocean. Prior to the arrival of French colonizers in Benin in 1855, the lake was an isolated freshwater lake supplied by the rivers Ouémé and Sô $^{1}$. In 1855, the French dug a lagoon canal connecting Cotonou's ocean coastline with Lake Nokoué in order to establish control over the port and maximize profits from the slave trade. The canal was widened in 1960 , creating a permanent exchange of fresh and salt-water between Lake Nokoué and the sea (Djihouessi et al., 2017). This exchange of fresh and salt-water is related to the water hyacinth because salinity above certain levels hinders water hyacinth growth.

\section{Step Two: Identify and Categorize Stakeholders}

While water hyacinth infestation and fish farming are problems in many parts of the world, the case study is chosen in Benin for two key reasons. First, Space Enabled was invited by Green Keeper Africa, a social enterprise located in Cotonou, Benin, to consider opportunities to start a project together. Second, a need for more research of environmental governance and DSSs in this particular location was identified. As water hyacinth infestation and anthropogenic pressure on ecosystems

${ }^{1}$ Global Nature. Available online at: https://www.globalnature.org/en/living-lakes/ africa/nokoue-lake.

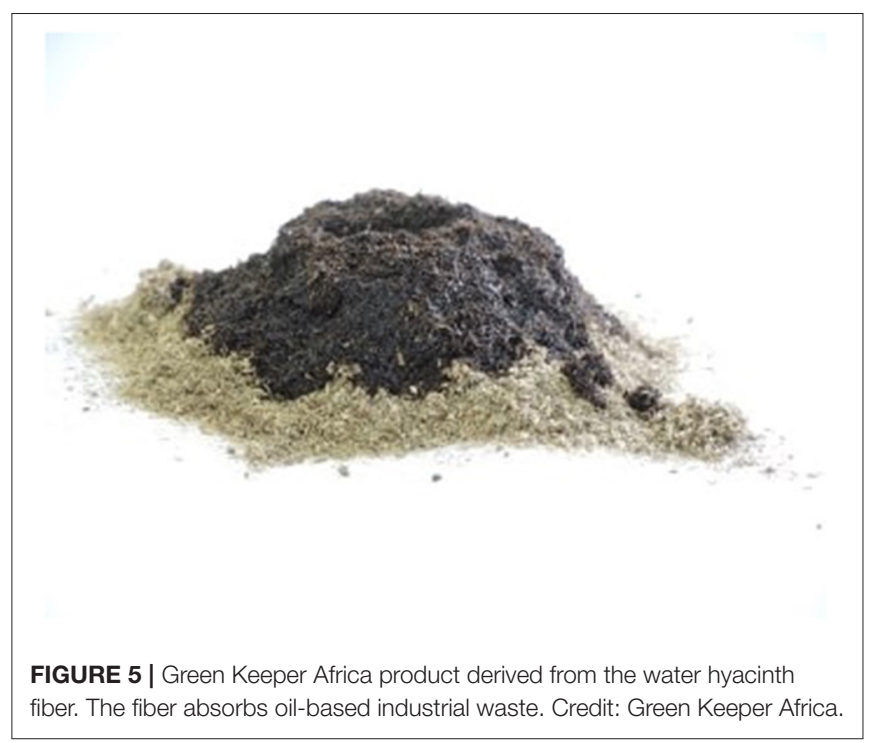

are common around the world, the hope is that research done in this case study can impact regions with similar environmental and demographic characteristics.

Green Keeper Africa (GKA) is led by Managing Director Dr. Fohla Mouftaou. GKA employs a combination of physical removal and commercialization to address the water hyacinth problem (Green Keeper Africa). At the time of this writing, GKA has an office in Cotonou, a warehouse on the Eastern part of the lake in Sô-Ava, the town in the land immediately northwest of Lake Nokoué, and a manufacturing site in Sémé. The company pays local community members to harvest the water hyacinth from Lake Nokoué, on the southern coast of Benin. After harvesting, the plant is transformed into a product that is highly effective at absorbing oil-based industrial waste (see Figure 5). In 2017, Dr. Fohla Mouftaou met Professor Danielle Wood, Director of the Space Enabled Research Group at the MIT Media Lab, during the Global Entrepreneurship Summit in Hyderabad, India. Professor Wood presented about opportunities for entrepreneurs to apply satellite earth observation and other space enabled technologies as part of their business models. Dr. Mouftaou invited Professor Wood to visit Benin in April 2018 to learn about the operations of Green Keeper Africa. During this visit, Dr. Mouftaou and Professor Wood proposed a multi-year collaborative project for their teams to develop a locally operated observatory system to monitor and forecast key environmental variables in the Lake Nokoué ecosystem using data from satellites and other sensors. The teams involved in the project include Space Enabled, Green Keeper Africa, NASA Goddard, East Carolina University and the company Blue Raster. Blue Raster is a company that works to develop interactive mapping technology. The collaborators also include Beninese Scientists Dr. Felicien Badou, Dr. Belfrid Djihouessi and Dr. Daouda Mama, who all work in hydrology and remote sensing on Lake Nokoué. Several of the scientists are or have formerly been associated with the National Institute of Water (Institut National de l'Eau, abbreviated as INE, in French) which was established at 
the University of Abomey-Calavi as a central knowledge institute for water research and education. The lead author joined the Space Enabled Research Group in Fall 2018 and has since been the primary graduate student working on the project.

In this case study, GKA are considered the Primary Stakeholders. GKA has resources and motive to make direct decisions about the system via their harvesting practices. The National Institute of Water (INE) are Secondary Stakeholders because they produce science and recommendations for lake management. GKA collaborates with the INE to understand and contribute to management of the lake's health. Consequently, the work that the INE produces may influence GKA's activities. Secondary Stakeholders in the system also include GKA investors and the National Government. There are at least three government entities that may have authority to regulate lake activities impacting GKA. These include the Ministry of the Living Environment and Sustainable Development, the Ministry of Agriculture, Livestock and Fisheries, and the Ministry of Water and Mines. Tertiary Stakeholders include GKA's harvesters, people that directly participate in activities with the lake, such as fishing, acadja construction or boating, and the broader Lake Nokoué community that live on or near the lake. This group of Stakeholders have influence over the Lake Nokoué system in that their activities can impact the health state of the lake both positively and negatively. They do not directly have authority or influence over GKA's activities, but they can be impacted by their activities. This group of Stakeholders can derive benefits from the lake or be harmed by the ecological state of the lake. Table 1 summarizes the Stakeholders and their categories in this system.

\section{Steps Three - Five: Describe Stakeholder Desired Outcomes, System Objectives, and Current Functions and Forms}

The purposes of Steps 3-5 of the SAF are to describe Stakeholder Desired Outcomes, identify System Objectives and describe current Functions and Forms. These steps of the SAF are applied with only Primary Stakeholder Green Keeper Africa. This decision is made for several reasons. Many of the lake communities speak local languages such as Fon and Yoruba that the author and many members of GKA do not speak. However, GKA has spent several years developing rapport with the Lake Nokoué communities. There is a specific role in the company dedicated to maintaining positive relationships with the communities. This team member speaks the language, convenes with community leaders, and aims to represent their interests while also advancing GKA's interests as a business. Space Enabled does not possess the capabilities to directly speak with

TABLE 1 | Summary of stakeholders in the system.

\begin{tabular}{|c|c|c|c|}
\hline & Primary & Secondary & Tertiary \\
\hline Description & $\begin{array}{l}\text { those that make direct decisions about the } \\
\text { design of the system }\end{array}$ & $\begin{array}{l}\text { those that have influence on the Primary Stakeholders } \\
\text { via authority or funding }\end{array}$ & $\begin{array}{l}\text { those that exert little or no control over the } \\
\text { system but are impacted by it }\end{array}$ \\
\hline Stakeholders & - Green Keeper Africa & $\begin{array}{l}\text { - National Institute of Water } \\
\text { - GKA investors } \\
\text { - Benin government ministries }\end{array}$ & $\begin{array}{l}\text { - People who participate in Fishing or Acadja } \\
\text { practices } \\
\text { - GKA harvesters } \\
\text { - Lake Nokoue community and surrounding } \\
\text { cities }\end{array}$ \\
\hline
\end{tabular}

Stakeholders are described as Primary, Secondary, and Tertiary.

TABLE 2 | Summary of qualitative data collected to inform steps 3-5 of the SAF.

\begin{tabular}{ll}
\hline Data type & Justification \\
\hline Interview with GKA CEO, Dr. & $\begin{array}{l}\text { This data collection is necessary to understand the company's } \\
\text { Fohla Mouftaou }\end{array}$ \\
& workflows that are active within GKA. An understanding of the \\
& manufacturing process can help the collaboration team identify an \\
& opportunity for the Decision Support Tool to support the high-level \\
& critical functions of the organization.
\end{tabular}

Observation of GKA harvesting This data collection is necessary to understand the people process

Observation of GKA Manufacturing Process involved in GKA's business model, local community methods used in harvesting processes, and variability between harvesting methods. An understanding of the harvesting process can help the collaboration team identify an opportunity for the Decision Support Tool to support this branch of GKA's activities.

This data collection is necessary to understand the series of steps necessary to produce GKA's commercial product and challenges with the current manufacturing process. An understanding of the manufacturing process can help the collaboration team identify an
opportunity for the Decision Support Tool to support this branch of GKA's activities.

\section{Collection method}

Ufuoma conducted a virtual interview with Dr. Fohla Mouftaou in March 2020 via Skype. The interview questions were prepared in collaboration with Blue Raster. The interview included open-ended questions on the following topics: GKA organizational structure, company objectives, company priorities, company goals and company metrics of success.

In January 2019, Professor Wood and Ufuoma Ovienmhada traveled to Cotonou for 3 weeks. Ufuoma spent a full day shadowing GKA employee Exacué Totin traveling by boat to several of the communities that harvest water hyacinth. Ufuoma asked Exacué questions directly and some to translate into the community's local language.

Ufuoma spent the majority of the January 2019 visit working alongside Florent Liaigre, the Manager of GKA's Manufacturing and Engineering team. Ufuoma interviewed Florent on all of the steps used in the manufacturing process 
these communities to understand their priorities with depth. However, in line with the collaboration model described in Section 2.2, Space Enabled trusts that GKA, as a social enterprise, has the harvester communities' best interests in mind. Thus, the data collection described below is performed under the assumption that GKA is aware of and communicates the interests of the harvesters and larger Lake Nokoué communities, with the ultimate goal of enabling long-term sustainable use of the lake. The authors recognize that this assumption could produce research that is exclusive of minority viewpoints, however this assumption is validated through direct observation as described later in this section.

Steps 3-5 are addressed through virtual interactions and physical visits to Cotonou where qualitative research was conducted with the primary stakeholder, GKA. These field visits further help to describe the context in Step 1. The inputs to Step 3, 4 and 5 are populated through interview with the GKA CEO, observation of the GKA harvesting process and observation of the GKA manufacturing process. Table 2 provides a summary and justification of the qualitative data collected for this step of the research. The data collected are then analyzed and summarized through interview coding techniques and flowchart visualizations for Steps $3-5$ of the SAF. In qualitative research, coding is the process of labeling and organizing your qualitative data to identify different themes and the relationships between them. In summarizing the three sets of data, the author used the following labels: Needs, Values, Desired Outcomes, Functions, Forms and Challenges. Needs are defined broadly as anything GKA perceives as a gap in a desired state, which may include their own business needs, or needs of the broader community context they work in. Values describe how GKA wants to approach those needs and what types of tradeoffs may be welcomed. The authors want to propose technology designs that are in line with and advance these values. Desired Outcomes are the present and future goals that GKA has for themselves as a company. Functions and Forms are the activities, tools, and techniques that GKA utilizes in order to achieve their Desired Outcomes. Challenges are barriers to achieving the system Desired Outcomes. Summaries of the analysis of each data are in the following section.

\section{Interview With GKA CEO}

Interview with GKA CEO: The interview was conducted on March 25th, 2020, using Skype. The interview was a duration of $1 \mathrm{~h}$ and $3 \mathrm{~min}$. It was recorded and transcribed for coding analysis. The lead author conducted the interview. The author summarized the findings of the interview using the aforementioned labels.

Needs - Green Keeper Africa is a for-profit company. While holding onto social and ecological impact goals, GKA must remain profitable. This has consequences for their activities. Harvesting, transporting, manufacturing, and storing the water hyacinth all require costs. As a result, the capacity GKA has to harvest the water hyacinth is dictated by demand for their product and services. GKA must have a market for the transformed water hyacinth product in order to maintain operation as a company. In addition to demand, GKA must have a labor supply local to where the water hyacinth appears. Challenges - GKA prefers not to employ harvesters to harvest in communities that the harvesters are not from because this presents a series of logistical challenges including drying space and transportation. Sometimes GKA wants to harvest in an area

TABLE 3 | Summary of the system stakeholders, forms, functions, and desired outcomes (from the perspective of GKA).

\begin{tabular}{|c|c|c|}
\hline Organizational team (forms) & ID & Functions \\
\hline \multirow[t]{3}{*}{ Supply chain } & F.1 & Set water hyacinth raw material price \\
\hline & F.2 & Recruit harvesting communities \\
\hline & F.3 & Organize supply transportation \\
\hline \multirow[t]{2}{*}{ Manufacturing } & F.4 & Secondary drying process \\
\hline & F.5 & Process water hyacinth raw material into commercial products \\
\hline Research and development & F.6 & Explore and experiment with new commercial futures for the water hyacinth product \\
\hline \multirow[t]{3}{*}{ Commercial } & F.7 & Identify customers \\
\hline & F.8 & Marketing \\
\hline & F.9 & Inform production \\
\hline \multirow[t]{4}{*}{ Finance } & F.10 & Product purchases \\
\hline & F.11 & Transportation of products \\
\hline & F.12 & Storage of products \\
\hline & F.13 & Technology purchases \\
\hline \multirow[t]{4}{*}{ Social impact } & F.14 & Monitor social impact \\
\hline & F.15 & Monitor economic impact \\
\hline & F.16 & Monitor environmental impact \\
\hline & F.17 & Train community in entrepreneurship activities \\
\hline \multirow[t]{2}{*}{ Management } & F.18 & Identify new markets \\
\hline & F.19 & Oversee entire company business \\
\hline
\end{tabular}

Green Keeper Africa allocates Forms which execute Functions that meet their Objectives. 
but there is not a labor supply either because there are better income alternatives or because the ecological and socioeconomic value of water hyacinth removal is not well-understood and quantified. Values - While GKA is a for-profit company, they also self-describe as a "social enterprise." A social enterprise is a cause-driven business whose primary reason for being is to improve social objectives and serve the common good. They go beyond the motive of maximizing profit for the company. Rather, there are a set of stakeholders (which includes the company itself) whose benefits they aim to maximize. Thus, they approach meeting the Needs of the company with several values. First, GKA wants the company to be "a development tool for the country, demonstrating low-tech approaches to local innovation.” Fohla described a desire to show that innovation can be accessible for varying levels of technological capabilities. Second, GKA wants to involve the community members in the business model. GKA's business model employs local community members and GKA aims to develop products that improve the environment of the community members. Thus, GKA's activities should not only bring economic benefit to harvesters through the employment, but also economic, social and health benefit by removing the threats to their ecosystem services. It is important to GKA that the need for profit does not betray social and environmental objectives. Desired Outcomes - Green Keeper Africa has three high-level desired outcomes.

1. Designing the Harvesting Strategy: Green Keeper Africa wants to harvest water hyacinth in a way that has the most environmental and social impact. This desired outcome relates to both local strategy and strategy for new facility sites in different locations. For example, GKA wants to consider creating a new facility in Ivory Coast, a country in West Africa that faces similar challenges with the water hyacinth. GKA wants to be able to characterize the hyacinth availability and behavior of the water hyacinth in this area. To provide another example, a community has requested that GKA consider beginning activities on the River Mono in Benin. They currently do not have the ability to efficiently assess the viability of their business model in this region. Challenges Achieving environmental and social impact must be done in a way that is cost-effective and profitable. GKA currently does not possess capabilities to quantitatively forecast the viability of their efforts in different regions.

2. Technology Capability Building: It is important to GKA to advance their technological knowledge and capabilities in order to advance local innovation and environmental governance. GKA wants to be a local provider of scientific information such as water quality or the impact of acadja practices that can be used by community members or authorities to improve lake management. For example, GKA would like to be able to characterize the acadja practice for government entities like the Ministry of the Living Environment and Sustainable Development, the Ministry of Agriculture, Livestock and Fisheries, and the Ministry of Water and Mines. Challenges - GKA has limited exposure to the applications of certain technologies. For the acadja application specifically, there are no formally documented methods for applying satellite Earth Observation for the acadja management. Water quality sensing is generally expensive and time-intensive to pursue

3. Local entrepreneurship support: GKA wants to partner and empower the community, in particular women and young people, to develop their own innovative businesses that harvest the water hyacinth material, or other sustainable materials.

Forms and Functions - GKA has seven discrete teams within their larger organization. Each team (form) is responsible for a set of functions that are pursued to address the company needs, values and desired outcomes related to harvesting, technology capability building, and local entrepreneurship support. Table 3 summarizes the functions of GKA's different organizational departments.

\section{Observation of GKA Harvesting Process}

On a Saturday in January 2019, this observation began with a drive to Porto-Novo with Exacué Totin who is the lead for GKA's community engagement with Ganvié. Forms and Functions Exacués job as Procurement Officer (form) is to manage the entire supply chain of the water hyacinth (function). This role involves interacting with village leaders, recruiting workers, overseeing the supply quality, and organizing transportation of the raw material to the main GKA manufacturing site. The trip began in the morning at $\sim 9$ A.M. Upon arriving at a dock in Porto-Novo, Ufuoma (first author) and Exacué entered a boat with several drivers. For this trip, Ufuoma carried a water quality sensor kit to practice taking measurements on the Lake. The boat would stop in certain places to take water measurements. The purpose of this was not for robust measurements but to understand how mobile the sensor kit prototype was and any challenges with collecting data in this fashion. Throughout the trip, Ufuoma asked Exacué questions to understand his responsibilities as a Procurement Officer. They traversed the river Ouémé and docked the boat at several communities in the town of Aguégués. Aguégués covers an area of 52 square kilometers. The most recent population count in 2002 estimated that the community is home to 26,000 people. Naturally, this population may be larger 18 years later. At each community, Exacué was greeted by the village leaders and many other community members. Values - It is important to GKA to have a strong rapport with the communities that they work with. Exacue is respected by and offers respect to the leaders in each community they work in. Forms - At the beginning of each harvesting cycle, a fixed price is set for the water hyacinth raw material by weight. This price is adjusted for different levels of quality. Upon arrival in a harvesting site, the village leader would lead Ufuoma and Exacué to a holding site for the hyacinth. The hyacinth were bound together into bushels using the hyacinth roots themselves. The holding sites were typically in open-air buildings for the water hyacinth to dry. In some cases, the holding sites were partially indoors for drier, transport-ready hyacinth material. The village leaders would show Exacué examples of the dried water hyacinth to examine quality. Exacué would offer feedback on the quality of the samples, then discuss timelines 
and logistics for transporting the dried bushels to the GKA manufacturing site in So Ava. GKA primarily employs women as harvesters because they are a population that would otherwise not have a consistent source of income. At some communities, there were women actively engaged in removing water hyacinth from the water. No technologies were observed in the process.

At intervals guided by the village leaders' input, Exacué organizes large boats to procure the bushels from each harvesting community and transport large shipments to the manufacturing site in So Ava. When GKA has specific orders placed, they call the local leaders to estimate water hyacinth presence and amount. Upon arrival, the bushels are weighed and inspected for quality to calculate the value of the raw material to pay the harvesters. The only observed technology used in the harvesting process is the scale. Challenges - relying on in-person observation to estimate water hyacinth amount is not precise and can be time-intensive.

\section{Observation of GKA Manufacturing Process}

Ufuoma spent the majority of the January 2019 trip working alongside Florent Liagre, GKA's Technical Manager who oversees the manufacturing process. Florent is trained in Mechanical Engineering. GKA's manufacturing site is strategically located close to the Lake and harvesting communities. Ufuoma and Florent traveled to So Ava three to four times during the January trip. Forms - The site at So Ava is a multi-unit partially enclosed building with a large uncovered open area. Functions - The open area is used as a home to the bushels transported from the harvesting communities. The bushels are left alone for several days for a secondary drying period. No technologies are used for drying. Thus, drying varies widely depending on the local weather conditions. Half of the building contains heavy-duty machinery that is used to transform the hyacinth from the raw material. During these visits, Ufuoma asked Florent to walk through each of the machines used in the process. In total, there are seven steps of the process from raw material to the commercial product phase. Weight and quality measurements are taken at multiple steps of the process. Ufuoma observed a live manufacturing process from start to finish. The other half of the building is used as storage for sale-ready product. Generally, because the water hyacinth is so prolific and the harvest is done in seasons, GKA has more supply of product than demand. In addition, GKA has undergone several stages to improve the quality of their products, thus some of the supply is of previous versions.

\section{System Objectives}

Sections Interview with GKA CEO-Observation of GKA Manufacturing Process identified the Needs, Values, Desired Outcomes, Functions, Forms and Challenges for the system comprising Green Keeper Africa and Lake Nokoué. In the SAF, there are often multiple sets of Desired Outcomes from one stakeholder or based on different stakeholders. The Space Enabled Research Lab has a high-level Desired Outcome to "advance justice in Earth's complex systems using designs enabled

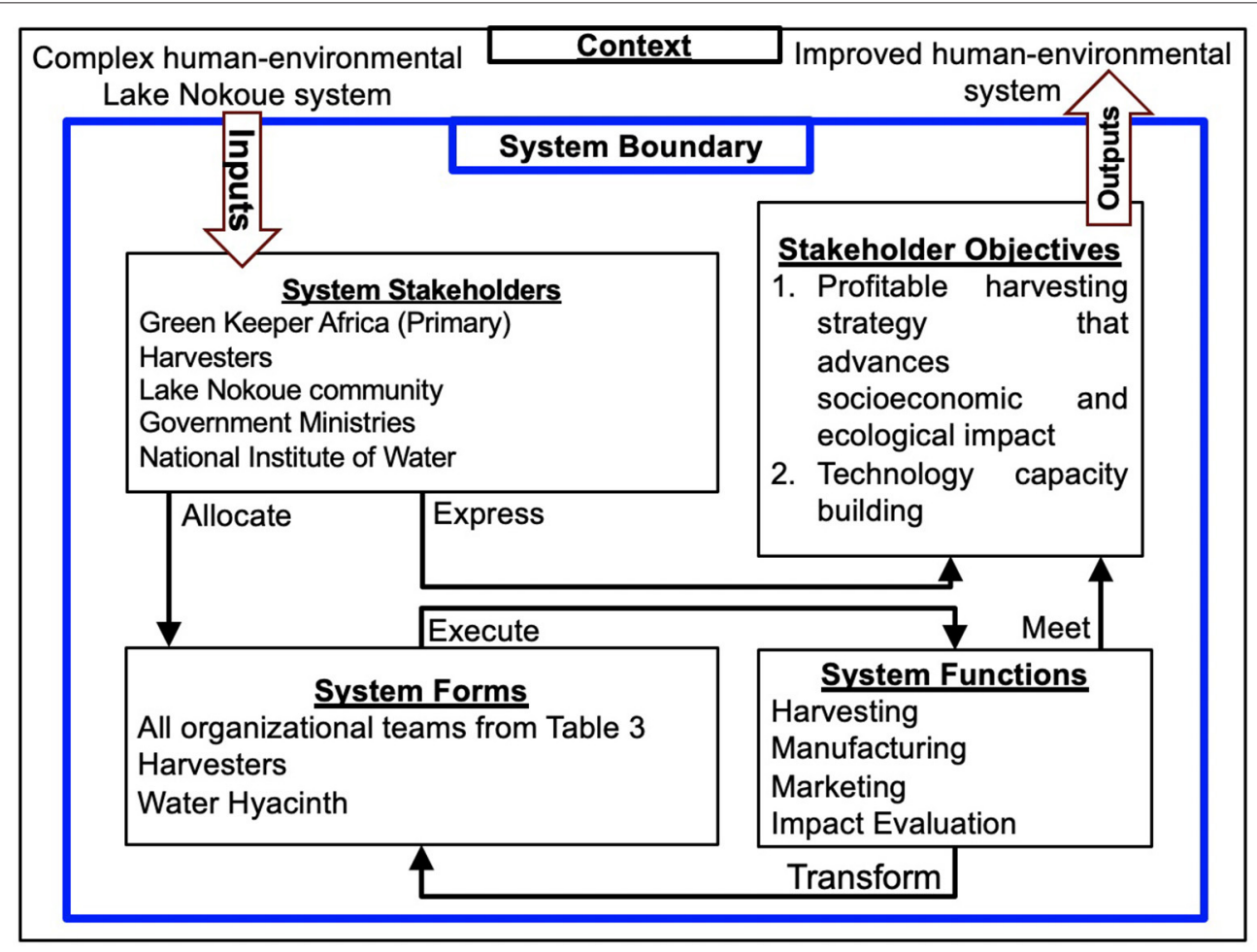

FIGURE 6 | Summary of the system Stakeholders, Forms, Functions and Desired Outcomes (from the perspective of GKA). GKA allocates forms which execute functions that meet their objectives. Credit: The Authors. 
by space" that comes from the lab mission statement. System Objectives are down selected from shared Desired Outcomes among the different Stakeholders considered in this analysis. Considerations for the down selection are time, cost, and expertise constraints. Based on Shared Desired Outcomes and considerations of constraints, the System Objectives identified for the technology design are (1) Profitable Harvesting Strategy that advances socioeconomic and ecological impact and (2) Technology Capacity Building. Figure 6 shows a visual summary of this information, excluding the Values and Challenges.

\section{Step Six: Describe Proposed Functions and Forms and Evaluate Them According to the System Objectives}

The previous section identified the Needs, Values, Desired Outcomes, Current Functions and Forms, System Objectives and Challenges for the system comprising Green Keeper Africa and Lake Nokoué. Connecting the stakeholder System Objectives to the Challenges enables the Systems Architects to identify areas where new Forms and Functions may better address the Stakeholder Objectives. From the observational research with Exacué and the interview with the CEO, it seems that the harvesting strategy is currently driven primarily by the locations of communities that want to engage in the harvesting practices. However, the CEO hopes that it could be driven by other factors as well such as mitigating the environmental and economic harm posed by the hyacinth. Enabling this requires a method for water hyacinth detection and forecasting, combined with geolocated demographic information. This System Objective also requires an ability to monitor where and how much GKA has harvested, an estimate of the value of the ecosystem services protected as a result of harvesting and framing all of this information to recruit harvesters. The Stakeholder Objective of building GKA's technology capacity requires an exploration of technologies and methods that contribute to the scientific knowledge of Lake Nokoué. The two priorities for this are defined by GKA as monitoring the acadja practice and water quality. Table 4 summarizes this information.

As shown in Table 4, there are several Forms that could advance GKA's System Objectives. These Forms should improve upon or execute new Functions and meet Stakeholder Objectives. Figure 7 depicts how these Forms would interact with the system to meet Stakeholder Objectives and improve the overall humanenvironmental system. All of these Forms are enabled by Earth Observation measurements including satellite, in-situ and aerial data. Water quality measurements use a combination of lowcost sensors designed specifically for the Lake Nokoue context. Water Hyacinth detection uses historical satellite data from the Landsat series, combined with spectral analysis and change detection techniques. Acadja detection uses Synthetic Aperture Radar data from Sentinel-1 and a Random Forest Machine learning algorithm. Developing these methodologies was not a straightforward process. It included literature review of the state of the art, challenges with data availability or applicability for the Cotonou context, and a constant effort to minimize costs. The full technical specifications of each of these Forms for the DSS are described in further detail in Ovienmhada (2020) and will be expanded on in future publications. While the DSS is not yet complete, it is regularly evaluated against the System Objectives as required by Step 6 of the SAF.

\section{Values in Action}

As outlined in section Selection of Technology Design Method, the authors developed four collaboration values to conduct an inclusive process that explicitly accounts for power imbalances. This section offers a reflection of how these values were relevant at different points in the collaboration.

The first value, "both partners aim to set project priorities based on needs identified within the host community," was about the approach to needs identification. We took an expansive approach, aiming to have as many in person exchanges as possible, and multiple ways of knowing through different types of data collection. The priorities were thus informed by multiple viewpoints.

The second value, "Green Keeper Africa invites Space Enabled to contribute to work in their community. Space Enabled trusts Green Keeper Africa to advise about how to operate within the local context and how to connect with relevant stakeholders," is about operating respectfully in a different context. This value was particularly relevant during the interactions with Exacué and the harvesting communities. We took our cues from Exacué on appropriate questions to ask and what types of greetings to offer considering the language difference. Green Keeper Africa helps the collaboration team accomplish our shared goals by introducing us to relevant local organizations and professionals.

The third value, "Both Space Enabled and Green Keeper Africa aim to learn from the expertise of local organizations about the project topic" is about valuing local knowledge generation. We draw on literature from Beninese scientists, Dr. Djihouessi and Dr. Badou, and collaborate with them directly to get feedback on our approaches and results. Reviewing local research took more effort than most literature reviews done in Western contexts because much of the work is in French. However, if we had not valued local research, we may have produced redundant results. We brought together the latest Beninese academic work, with expertise from NASA, MIT, GKA, ECU and Blue Raster to push forward the application of satellite data for water hyacinth and acadja detection.

The fourth value, "Space Enabled and Green Keeper Africa make decisions collaboratively regarding how to fundraise, speak publicly about the work, spend funds, bring on new team members and set project objectives." This project is made possible by several sources of funding which are all reviewed for how best to support the collaboration teams. In publishing, parties from all teams are considered for co-authorship and have an opportunity to contribute to academic writing, such as in this paper.

\section{DISCUSSION}

The authors began the study by describing the complex nature of human-environmental systems and challenges to effective Environmental Governance. There are many concrete ways 
TABLE 4 | Summary of challenges related to stakeholder system objectives and proposed forms that could address these challenges.

\begin{tabular}{|c|c|c|}
\hline System objectives & Challenge & Potential form \\
\hline \multirow{6}{*}{$\begin{array}{l}\text { Profitable harvesting strategy that advances } \\
\text { socioeconomic and ecological impact }\end{array}$} & Historical understanding of water hyacinth & Method for water hyacinth detection \\
\hline & Forecasting water hyacinth & $\begin{array}{l}\text { Historical understanding of water hyacinth and } \\
\text { parameters that can be used for prediction }\end{array}$ \\
\hline & $\begin{array}{l}\text { Measuring GKA socioeconomic and ecological } \\
\text { impact }\end{array}$ & $\begin{array}{l}\text { Ability to monitor where and how much GKA has } \\
\text { harvested }\end{array}$ \\
\hline & & $\begin{array}{l}\text { Quantitative understanding of lake health including water } \\
\text { quality and acadja }\end{array}$ \\
\hline & & Value of Ecosystem Services \\
\hline & Harvester supply & Local benefit of water hyacinth removal \\
\hline \multirow[t]{3}{*}{$\begin{array}{l}\text { Technology Capacity Building (e.g., Acadja Detection, } \\
\text { Water quality sensing) }\end{array}$} & $\begin{array}{l}\text { Limited exposure to the applications of certain } \\
\text { technologies. }\end{array}$ & Explore and train GKA in remote sensing applications \\
\hline & No documented methods for Acadja Detection & Method for acadja detection \\
\hline & $\begin{array}{l}\text { Water quality sensing is time-intensive and } \\
\text { expensive }\end{array}$ & Design of a low-cost water quality sensor \\
\hline
\end{tabular}

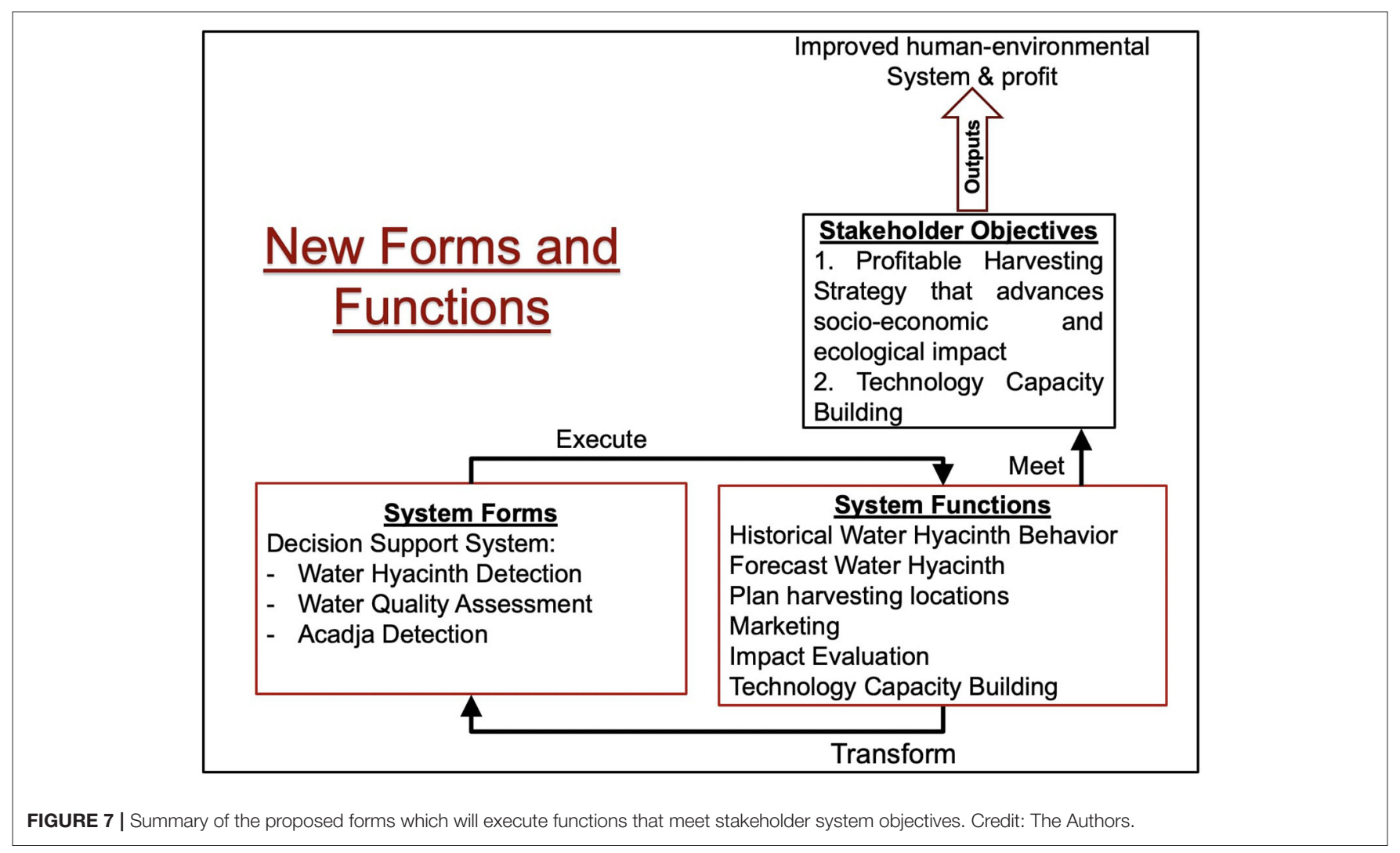

in which Earth Observation data can be applied for societal benefit, in particular as it relates to Environmental Governance, to support human decision- making in complex systems. The authors cited several challenges that prevent the communities that need it the most from harnessing the benefits of space technologies. With these challenges in mind, the author set out to simultaneously address the needs for Environmental
Governance and the challenges to implementation. The Research Objective, "Describe an inclusive process that an organization could take to design a DSS" was about exploring high-level frameworks, methodology, ways of thinking, and levels of collaboration. The research in section Materials and Methods explored these high-level topics by examining and critiquing different design methods that can be used for technology, 
product, or service development. Due to the complexity of the system of interest comprising Green Keeper Africa and their interactions with Lake Nokoué, the author determined that the SAF was the most relevant design method for the application. The authors strengthened the SAF through an explicit definition of principles to guide the collaboration model between Space Enabled, Green Keeper Africa, NASA Goddard, the Benin National Institute of Water and Blue Raster. Then, Steps 1-6 of the SAF were applied to generate descriptions of the Context, Stakeholders, Stakeholder Needs and Desired Outcomes, Desired System Objectives, and current Forms and Functions of the system. The first Stakeholder System Objective is that GKA wants to be able to design a profitable harvesting strategy that advances socio-economic and ecological impact. The second Stakeholder Objective is that GKA wants to develop technological capabilities to advance the innovation of their companies work and to support Environmental Governance of Lake Nokoué. The priorities for technological capabilities are monitoring acadja and the water quality of Lake Nokoué. These descriptions enabled the authors to construct a visual representation of the system relationships and opportunities for new Forms to better address the Stakeholder's System Objectives. The proposed new Form that would address System Objectives is a Decision Support System that contains information about the water hyacinth, acadja, and water quality.

This case study highlights several important findings study for those seeking to be inclusive in their climate data service design. First, all design methodologies are not created equal. A design method is not necessarily inclusive by virtue of valuing "empathy" in the design process because different design methods make implicit or explicit assumptions of who the designer should be empathizing with. This study offers ideas for several characteristics to critique when evaluating a technology design methodology for a particular context or application.

A second important finding is that inclusivity benefits from reflexivity, where reflexivity refers to the examination of one's own beliefs, judgments and practices during the research process and how these may have influenced the research (Finlay, 1998). The authors demonstrate reflexivity in the recognition that the SAF as a collaboration model could be bolstered through explicit definitions of guiding values for processes related to data collection, presentations, and fundraising. These guiding values have been and continue to be relevant in carrying the project forward in an inclusive manner. Reflexivity is also demonstrated in the acknowledgment of assumptions made in the application of the SAF. Acknowledging assumptions allows one to be aware of areas that may require additional context, in our case of the assumption made about GKA's relationship with harvesters, additional context was garnered through informal data collection.

Overall, the study demonstrated how the SAF could be used to summarize locally-defined priorities for a DSS from the viewpoint of a primary stakeholder. As described further in Ovienmhada (2020), this qualitative work enabled the collaboration team to develop EO methods that address GKA's priorities for water hyacinth and acadja detection and water quality measurements. Since the SAF is a cycle, the methodology sets up the team with a clear high-level rubric with which to evaluate the DSS.

Future analysis could aim to perform more in-depth analysis of Stakeholder Needs and Desired Outcomes. Specifically, it would be helpful to analyze viewpoints from other members of GKA, The National Institute of Water, and from people engaged in the acadja practice or community members at large. Interviews with the latter category should be pursued in collaboration with GKA in line with the collaboration principles outlined in section Selection of Technology Design Method. These interviews could further help to elucidate opportunities for new Forms to meet System Objectives from the viewpoints of these other Stakeholders.

This research has several broader implications. The multidisciplinary approach in this thesis produced scientific knowledge in response to locally defined priorities, while valuing local knowledge and emphasizing routine exchange as a form of research. New and Improved techniques were developed that directly address Stakeholder Needs related to Environmental Governance. In this process, the Primary Stakeholder, Green Keeper Africa, was exposed to a class of technologies that may potentially advance their capabilities and impact as a company. GKA and team Space Enabled have valued bringing in local Beninese students into the project to be trained in new skills. Thus, this work also contributes to the educational development of local students. Lastly, many coastal cities are facing similar challenges as Lake Nokoué with population pressure, environmental change and Benefit Dependencies amongst different Stakeholders that interact with the same environment. The authors hopes that the framework, principles, and ways of thinking demonstrated in this thesis will benefit these other communities around the world facing Environmental Governance challenges.

\section{DATA AVAILABILITY STATEMENT}

The original contributions presented in the study are included in the article/supplementary material, further inquiries can be directed to the corresponding author/s.

\section{ETHICS STATEMENT}

The studies involving human participants were reviewed and approved by MIT Institutional Review Board called the Committee on the Use of Human Experimental Subjects. The patients/participants provided their written informed consent to participate in this study. Written informed consent was obtained from the individual(s) for the publication of any potentially identifiable images or data included in this article.

\section{AUTHOR CONTRIBUTIONS}

DW and FM conceived the original project. DW supervised the project. UO carried out the data 
collections and analysis and took the lead in writing the manuscripts. UO and DW contributed to the interpretation of the results. All authors provided critical feedback that helped shape the research, analysis, and manuscript.

\section{FUNDING}

This work was funded by MISTI Africa, the Horowitz Fund, Media Lab Travel Fund, NASA Applied Sciences

\section{REFERENCES}

Barrett, S., and Forno, I. (1982). Style morph distribution in new world populations of eichhornia crassipes (mart.) solmslaubach (water hyacinth). Aquat. Bot. 13, 299-306. doi: 10.1016/0304-3770(82)90065-1

Boyd, J., and Banzhaf, S. (2007). What are ecosystem services? the need for standardized environmental accounting units. Ecol. Econ. 63, 616-626. doi: 10.1016/j.ecolecon.2007.01.002

Cameron, B., Crawley, E., and Selva, D. (2016). Systems Architecture. Strategy and Product Development for Complex Systems. New York, NY: Pearson Education.

Center, T. D. (1994). Biological control of weeds: waterhyacinth [Eichhornia crassipes] and waterlettuce [Pistia stratiotes]. Intercept Limited. Andover, United Kingdom.

Charudattan, R. (2001). Biological control of weeds by means of plant pathogens: significance for integrated weed management in modern agro-ecology. Biocontrol 46, 229-260. doi: 10.1023/A:1011477531101

Crawley, E., de Weck, O., Eppinger, S. D., Magee, C., Moses, Seering, W., et al. (2004). "The influence of architecture on engineering systems. The influence of architecture on engineering systems," MIT Engineering Systems Symposium (Cambridge, MA).

De Groote, H., Ajuonu, O., Attignon, S., Djessou, R., and Neuenschwander, P. (2003). Economic impact of biological control of water hyacinth in southern benin. Ecol. Econ. 45, 105-117. doi: 10.1016/S0921-8009(03)00006-5

Diana, C., Pacenti, E., and Tassi, R. (2012). "Visualtiles: Communication tools for (service) design," in Conference Proceedings ServDes 2009 DeThinking Service; ReThinking Design (Oslo: Linköping University Electronic Press).

Djihouessi, M. B., and Aina, M. P. (2018). A review of hydrodynamics and water quality of lake nokoué: Current state of knowledge and prospects for further research. Region. Stud. Marine Sci. 18, 57-67. doi: 10.1016/j.rsma.2018.01.002

Djihouessi, M. B., Aina, M. P., Kpanou, B. V., and Kpondjo, N. (2017). Measuring the total economic value of traditional sand dredging in the coastal lagoon complex of Grand-Nokoué (Benin). J. Environ. Prot. 8:1605. doi: 10.4236/jep.2017.813099

Dsikowitzky, L., Ferse, S., Schwarzbauer, J., Vogt, T. S., and Irianto, H. E. (2016). Impacts of megacities on tropical coastal ecosystems-the case of jakarta, indonesia. Mar. Pollut. Bull. 110:621. doi: 10.1016/j.marpolbul.2015.11.060

Dunigan, E. P., Phelan, R., and Shamsuddin, Z. (1975). Use of water hyacinths to remove nitrogen and phosphorus from eutrophic waters. Hyacinth Control J. $13,59-61$.

Finlay, L. (1998). Reflexivity: an essential component for all research? Br. J. Occup. Ther. 61, 453-456. doi: 10.1177/030802269806101005

Gichuki, J., Omondi, R., Boera, P., Okorut, T., Matano, A. S., Jembe, T., et al. (2012). Water hyacinth eichhornia crassipes (mart.) solms-laubach dynamics and succession in the nyanza gulf of lake victoria (east africa): implications for water quality and biodiversity conservation. Sci. World J. 2012:106429. doi: 10.1100/2012/106429

Hein, L., Van Koppen, K., De Groot, R. S., and Van Ierland, C. E. (2006). Spatial scales, stakeholders and the valuation of ecosystem services. Ecol. Econ. 57, 209-228. doi: 10.1016/j.ecolecon.2005.04.005

Hill, M., and Olckers, T. (2000). "Biological control initiatives against water hyacinth in south africa: constraining factors, success and new courses of action," In ACIAR proceedings, ACIAR.
Biodiversity and Ecological Forecasting Program (Grant number 80NSSC19K0205), MIT Solve, and the Emerson Collective.

\section{ACKNOWLEDGMENTS}

FM, CEO of Green Keeper Africa, created opportunities for field research and data collection which was supported by Exacué Totin. Space Enabled Undergraduate Researchers, Mulan Jiang and Aliza Camacho, contributed to background data collection, and analysis presented in this paper.

Holm, L., Weldon, L., and Blackburn, R. (1969). Aquatic weeds. Science 166, 699-709. doi: 10.1126/science.166.3906.699

Irwin, T. (2015). Transition design: A proposal for a new area of design practice, study, and research. Design Cult. 7, 229-246. doi: 10.1080/17547075.2015.1051829

Jafari, N. (2010). Ecological and socio-economic utilization of water hyacinth (eichhornia crassipes mart solms). J. Appl. Sci. Environ. Manage. 14:2. doi: 10.4314/jasem.v14i2.57834

Johnson, R. R., Salvo, M. J., and Zoetewey, M. W. (2007). User-centered technology in participatory culture: Two decades beyond a narrow conception of usability testing. IEEE Transact. Profess. Commun. 50, 320-332. doi: 10.1109/TPC.2007.908730

Julien, M. H., Griffi ths, M. W., and Stanley, J. N. (2001). Biological control of water hyacinth. The moths Niphograpta albiguttalis and Xubida infusellus: biologies, host ranges, and rearing, releasing and monitoring techniques. ACIAR Monograph No. 91, 16-18.

Lowe, S., Browne, M., Boudjelas, S., and De Poorter, M. (2000). 100 of the World's Worst Invasive Alien Species: A Selection From the Global Invasive Species Database, vol. 12. Auckland: Invasive Species Specialist Group.

Mailu, A., Ochiel, G., Gitonga, W., and Njoka, S. (1998). "Water hyacinth: an environmental disaster in the winam gulf of lake victoria and its control," in Proceedings of the First IOBC Global Working Group Meeting for the Biological and Integrated Control of Water Hyacinth (Harare).

Mangas-Ramírez, E., and Elías-Gutiérrez, M. (2004). Effect of mechanical removal of water hyacinth (eichhornia crassipes) on the water quality and biological communities in a mexican reservoir. Aquat. Ecosyst. Health Manag. 7, 161-168. doi: 10.1080/14634980490281597

Martin, J. (2008). Using architecture modeling to assess the societal benefits of the global earth observation system-of-systems. IEEE Syst. J. 2, 304-311. doi: 10.1109/JSYST.2008.925974

McGranahan, G., Balk, D., and Anderson, B. (2007). The rising tide: assessing the risks of climate change and human settlements in low elevation coastal zones. Environ. Urban. 19, 17-37. doi: 10.1177/0956247807076960

Monroe, J. C. (2011). In the belly of dan: space, history, and power in precolonial dahomey. CurCurr. Anthropol. 52, 769-798. doi: 10.1086/662678

National Public Radio (2019). Jakarta. Available online at: https://www.npr.org/ 2019/04/29/718234878/indonesia-plans-to-move-its-capital-out-of-jakartaa-city-thats-sinking (accessed March 15, 2020).

Niyonkuru, C. and Lalèyè P. (2010). Impact of acadja fisheries on fish assemblages in lake nokoué, benin, west africa. Knowl. Manage. Aquatic Ecosys. 399:5. doi: $10.1051 / \mathrm{kmae} / 2010033$

Norman, D. A. (2005). Human-centered design considered harmful. Interactions 12, 14-19. doi: 10.1145/1070960.1070976

Northern Arizona University (2008). GC-Choctaw. Available online at: https:// www7.nau.edu/itep/main/tcc/Tribes/gc_choctaw (accessed March 15, 2020).

Ovienmhada, U. (2020). Earth Observation Technology Applied to Environmental Management: A Case Study in Benin. Doctoral dissertation, Massachusetts Institute of Technology. Available online at: https://hdl.handle.net/1721.1/ 127489

Pratomo, J. (2016). Transferability of The Generic and Local Ontology of Slum in Multi-temporal Imagery, Case Study: Jakarta. PhD thesis, Master's Thesis, University of Twente, Enschede, The Netherlands. 
PRB (2020). Ripple Effects: Population and Coastal Regions. Available online at: https://www.prb.org/rippleeffectspopulationandcoastalregions/. (accessed March 2020).

Rechtin, E., and Maier, M. W. (2010). The Art of Systems Architecting. Boca Raton, FL: CRC Press. doi: 10.1201/9781420058529

Sanders, E. B. N., and Stappers, P. J. (2008). Co-creation and the new landscapes of design. Co-design 4, 5-18. doi: 10.1080/15710880701875068

Service Planning Toolkit (2017). Available online at: https://www.servirglobal. net/Portals/0/Documents/ServicePlanningToolkit_2017-09-19.pdf (accessed August 20, 2021).

SERVIR Service Catalogue (2018). Available online at: https://servirglobal.net/\# servicecatalogue (accessed March 2020).

Soumonni, E. (2003). "Lacustrine Villages in South Benin as Refuges From the Slave Trade." Fighting the slave trade: West African strategies.

The World Factbook (2021). Benin: People and Society. Available online at: https:// www.cia.gov/the-world-factbook/countries/benin/\#people-and-society. (accessed April 2021).

Turner, B. L., Kaspeson, R. E., Matson, P. A., McCarthy, J. J., Corell, R. W., Christensen, L., et al. (2003). A framework for vulnerability analysis in sustainability science. Proc. Nat. Acad. Sci. U.S.A. 100, 8074-8079. doi: $10.1073 /$ pnas. 1231335100

Verma, R., Singh, S., and Raj, K. (2003). Assessment of changes in water-hyacinth coverage of water bodies in northern part of Bangalore city using temporal remote sensing data. Curr. Sci. 84, 795-804. Available online at: http://www. jstor.org/stable/24107584

Villanueva, M. C., Laléyé P., Albaret, J.-J., Lae, R., de Morais, L. T and Moreau, J. (2006). Comparative analysis of trophic structure and interactions of two tropical lagoons. Ecol. Modell. 197, 461-477. doi: 10.1016/j.ecolmodel.2006.03.016
Weis, A. (2020). Gnf - nokoué lake. Available online at: https://www. globalnature.org/en/living-lakes/africa/nokoue-lake (accessed August 20, 2021).

Welcomme, R. (1971). A description of certain indigenous fishing methods from southern dahomey. Afr. J. Trop. Hydrobiol. Fish. 1, 129-140.

Welcomme, R. (2002). An evaluation of tropical brush and vegetation park fisheries. Fish. Manag. Ecol. 9, 175-188. doi: 10.1046/j.1365-2400.2002. 00292.x

Wood, D., and Weigel, A. (2014). Architectures of small satellite programs in developing countries. Acta Astronaut. 97, 109-121. doi: 10.1016/j.actaastro.2013.12.015

Conflict of Interest: The authors declare that the research was conducted in the absence of any commercial or financial relationships that could be construed as a potential conflict of interest.

Publisher's Note: All claims expressed in this article are solely those of the authors and do not necessarily represent those of their affiliated organizations, or those of the publisher, the editors and the reviewers. Any product that may be evaluated in this article, or claim that may be made by its manufacturer, is not guaranteed or endorsed by the publisher.

Copyright (C) 2021 Ovienmhada, Mouftaou and Wood. This is an open-access article distributed under the terms of the Creative Commons Attribution License (CC BY). The use, distribution or reproduction in other forums is permitted, provided the original author(s) and the copyright owner(s) are credited and that the original publication in this journal is cited, in accordance with accepted academic practice. No use, distribution or reproduction is permitted which does not comply with these terms. 